\title{
MICROELECTRODE STUDIES ON SENSORY AFFERENTS IN THE POSTERIOR FUNICULUS OF CAT
}

\author{
SINZIRO YAMAMOTO, SOTOO SUGIHARA \\ Surgical Clinic, Kanazawa University School of Medicine, Kanazawa \\ AND \\ MASARU KURU* \\ Second Surgical Clinic, Osaka University Medical School, Osaka
}

Among the fibres in the spinal cord, those in the posterior funiculus are characterized by their laminated arrangement. While it is generally assumed that they are concerned with the mediation of tactile sensation, some of the proprioceptive afferents are also said to be involved in the posterior funiculus (Fabritius (5), Foerster (7), Sjöqvist and Weinstein (25), Gardner and Noer (10)). White (30) has initiated the opinion that the sense of distension of the pelvic viscera may be also transmitted by them, based upon the clinical experience that this sense was still spared even after an extensive bilateral cut of the anterolateral fascicles. One of the authors, (M. K. (18)), has lucidly demonstrated in frog, cat and man the existence of a special component in the posterior funiculus which, originating in the posterior roots of the inferior segments of the cord, ascends in the paramedian superficial layer of the posterior funiculus to terminate in a column of grey matter (nucleus paraalaris) closely lateral to the ala cinerea in the medulla. In view of the ample correspondence between it and the sensory root of the vagus nerve he named this component "pelvic sensory vagus."

The aforementioned works suggest that the impulses ascending in the posterior funiculus may be more complex than had been supposed, comprising those originating in viscera. The experiments here described were made with a view of determining the adequate stimuli which can evoke action potentials in the posterior funiculus, paying special attention to pelvic visceral afferents.

METHODS

Ninety-two cats were used. Under ether anaesthesia trachea was canulated and common carotid arteries were ligated on both sides. After decerebration by the trephine method the anaesthetic was discontinued. The cerebellum was then removed with occipital craniotomy and successively vestibular nuclei and their surroundings were destroyed electrolytically on both sides to relieve the animal from decerebrate rigidity. In some cases, however, the rigidity was reduced or eliminated by removing the cerebellum only, and in such cases the

Received for publication October 23, 1955.

This work was carried out in the Neurological Laboratory of the Surgical Clinic, Kanazawa University School of Medicine and a part of it was preliminarily reported by Kuru, Yamamoto and Sugihara (19) in 1953.

*山本信二郎, 杉原外於夫, 久留 勝 
latter procedure could be dispensed with. Then, cutting the skin and muscles of the neck, the dorsal surface of the first to third cervical cord was exposed by laminectomy, and usually the second cervical cord was prepared for recording.

To evoke the action current in the posterior funiculus, no electrical, but the following adequate stimuli were used: touch on the pad of the foot or hair, push or pull of the skin, flexion or extension of joints. To exclude the afferents from the skin, in certain instances stimuli were directly applied on a muscle or an articular capsule after stripping off the skin. Distension of urinary bladder was effected in every animal by filling it with $29-40 \mathrm{cc}$. of body temperature water.

It was necessary to repeat the insertion of the electrode through the tenacious layer of pia mater to detect the receptive field in the body. For this purpose toughness was necessarily a requisite for the electrode. We found the silver electrode the most suitable, when insulated with a glass tube and coated with baked enamel. One end of the silver wire, about $0.3 \mathrm{~mm}$. in diameter, was sharpened as thin as possible by the electrolytically pointing technique. This needle was inserted into a glass tube of about $2 \mathrm{~mm}$. in diameter and drawn on a gas flame. The needle was thus tightly coated with a glass membrane, the tip being 5-10 $\mu$ in diameter. The surface of the electrode thus coated was, in addition, enamelled to protect the brittleness of the glass coating, and then the tip was ground slightly to expose the silver. Such electrodes were so tenacious that one of them endured over 500 insertions. The electrode was hung by a enamelled wire of approximately $60 \mu$ in diameter and was connected to a CR coupled amplifier. After insertion, the electrode was floated on the spinal cord by means of this flexible wire so that troubles induced by respiratory movements or arterial pulsation would be minimized. The indifferent electrode was attached to the bone or surface of the spinal cord in the neighbourhood.

For recording, an electromagnetic oscillograph was chiefly used. A cathoderay oscillograph was auxiliarily used for the distinction of the spike shapes. By use of a loud speaker as well as a repetitively sweeping oscillograph as monitors, the responses to adequate stimuli were properly recorded. After each recording, a circuit of negative direct current was applied, and a minute necrotic lesion was produced electrolytically to mark the site of the electrode tip.

Since a number of recordings were usually repeated in the same animal, each point of insertion of the electrode was marked with chinese ink on the pia and sketched precisely to avoid confusion. After a sufficient number of recordings were made, the animal was sacrificed, and the spinal cord was taken out to be fixed in Muiller's solution. The cervical segments of it were sectioned serially and staind by Weigert-Pal's method. Comparing the preparations with the above-mentioned sketch, the sites of recording could be precisely checked.

\section{RESULTS}

Spikes observed in this work had the appearance of a single unit recording, and they were not always simliar to those obtained in the posterior funiculus subsequent to electrical stimulation of the peripheral nerve (Gasser and Graham (11), Hursh (15), Therman (27)). Spikes obtained in the posterior funiculus caudad to the middle level of the second cervical cord were always initially 
positive and quite similar in appearance to those obtained in the peripheral nerve (fig. $1 \mathrm{~A}$ ). Considering the short time constant of the amplifier (1 msec.), spike appearance of this type may be virtually monophasic and similar to those obtained from nerve fibre using a capillary supermicroelectrode (Tasaki (26), Woodbury (31)). Most of recordings were to be attributed to this type, and the maximal value of spikes evoked by tactile stimuli was $1.05 \mathrm{mV}$. Cephalad to this level, especially in the posterior funiculus nuclei, spikes of the other type were frequently encountered. These were characterized by an initially negative phase which was sometimes preceded by a smaller positive deflection (fig. $1 B$, $a, b)$. The negative phase in the spikes of this type was so short in duration that we could distinguish them from those of the former type only by hearing impulse volleys with a loud speaker. The magnitude of potential of this type was usually smaller than the former, maximal value being about $200 \mu \mathrm{V}$.

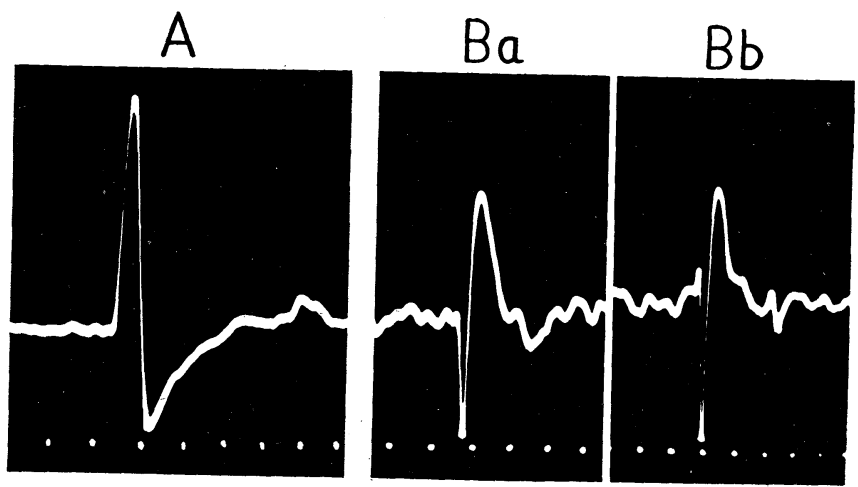

FIG. 1. Spike potentials recorded from the posterior funiculus. Upwards positive. Time constant of the amplifier is about $1 \mathrm{msec}$. Time in $1 \mathrm{msec}$.

$A$ : Impulse discharges generally recorded caudad to the middle of the second cervical level except in the vicinity of the grey matter.

$B, a, b$ : Impulse discharges frequently recorded in the vicinity of the posterior funiculus nuclei or in the grey matter of the spinal cord.

\section{CLASSIFICATION OF AFFERENTS IN THE POSTERIOR FUNICULUS}

Among the various responses obtained in the posterior funiculus at least the following four categories were substantially distinguished:

\section{1) Responses to tactile stimuli}

Tactile stimuli responses could be obtained most frequently, and were characterized by very quick adaptation. The amplitude of spikes was usually large. In regard to the construction of impulse volleys as well as to their adaptation, the responses obtained from touch afferents of the pad were quite similar to those obtained by movement of hair. Therefore, we considered these two types to be in one category. In some cases, responses to stimulation of different parts of the body could be recorded at one and the same point in the posterior funiculus. For example, recordings of impulse discharges " $A$ " and " $B$ " in fig. 2 correspond to touch on receptive fields " $a$ " and " $b$ " in the sketch of the same 
figure. Such a marked difference of spike heights, as shown in this example, responding to the same stimuli may depend on the distance between the electrode tip and the source of discharges rather than the calibre of the nerve fibre. The receptive area for tactile afferents varied markedly in different parts of the body. While it was as large as 2-3 centimeters square on the trunk, it was sometimes restricted to a few millimeters square or even to a point at the end of limbs. The area of the receptive field increases in the following order: toe, perineum, distal part of limbs, tail, proximal part of limbs and trunk. Because of the smallness of receptive area and the frequency of responses, the hairy toe area especially surrounding the nail, seems to be the most sensitive.
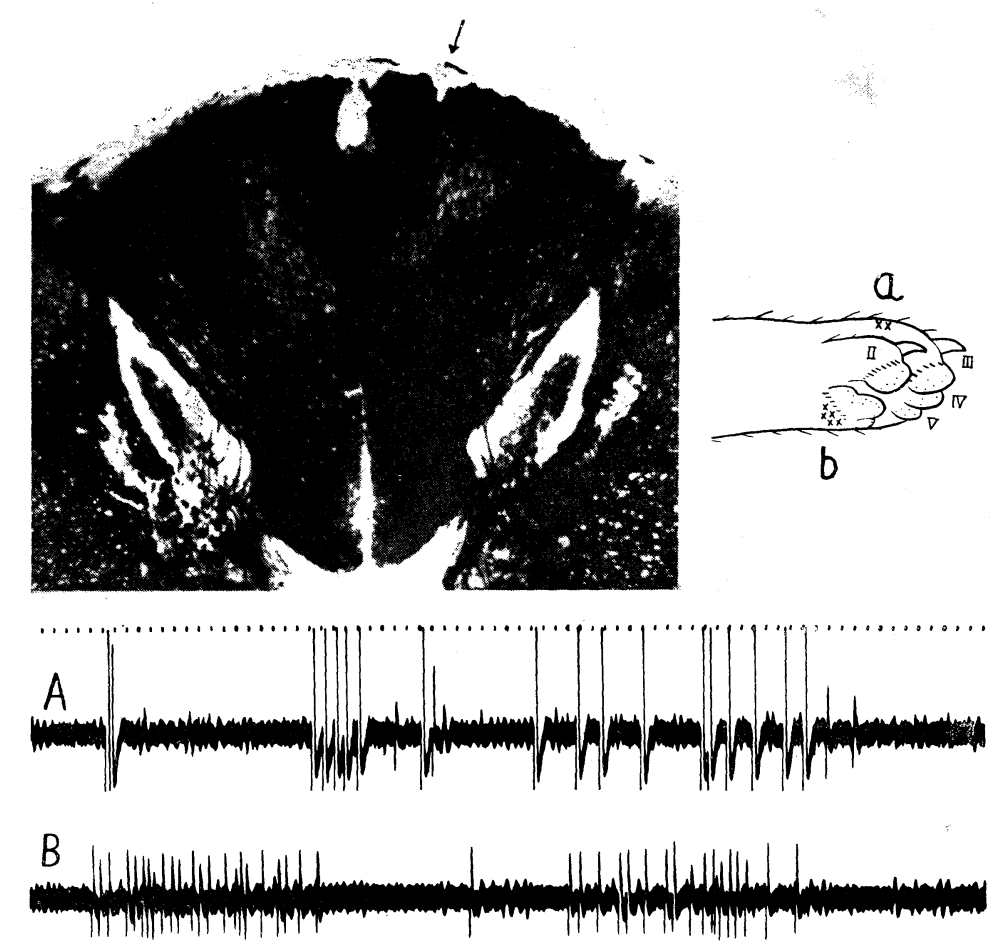

FIG. 2. Impulse discharges evoked by tactile stimuli. The site of recording is indicated with an arrow on the upper left figure (Weigert-Pal's stain). Responses from two different receptive fields were obtained from the same point. The necrotic area in the vicinity of the septum medianum is independent of this recording. Time in $1 / 120 \mathrm{sec}$.

$A$ : Responses evoked by strokes on the dorsum of the left third hind-toe corresponding to " $a$ " in the sketch.

$B$ : Responses evoked by strokes on the small area proximally adjacent to the plantar cushion corresponding to " $b$ " in the sketch.

2) Responses to push, pull or pinch of skin

In contrast to the tactile afferents, responses provoked by push, pull or pinch of the skin adapted slowly. Their adaptation varied from case to case. While 
in certain experiments impulse discharges were reduced to half within 10 seconds and extinguished in one minute from the beginning of stimulation, in others they continued for very long until the recording was interrupted by a shift of the electrode. In fig. 3 is illustrated such an example where impulses, evoked by pinching the skin of encircled area on the left loin with a spring-hinged paper clip, continued for over 40 minutes. These types of responses could
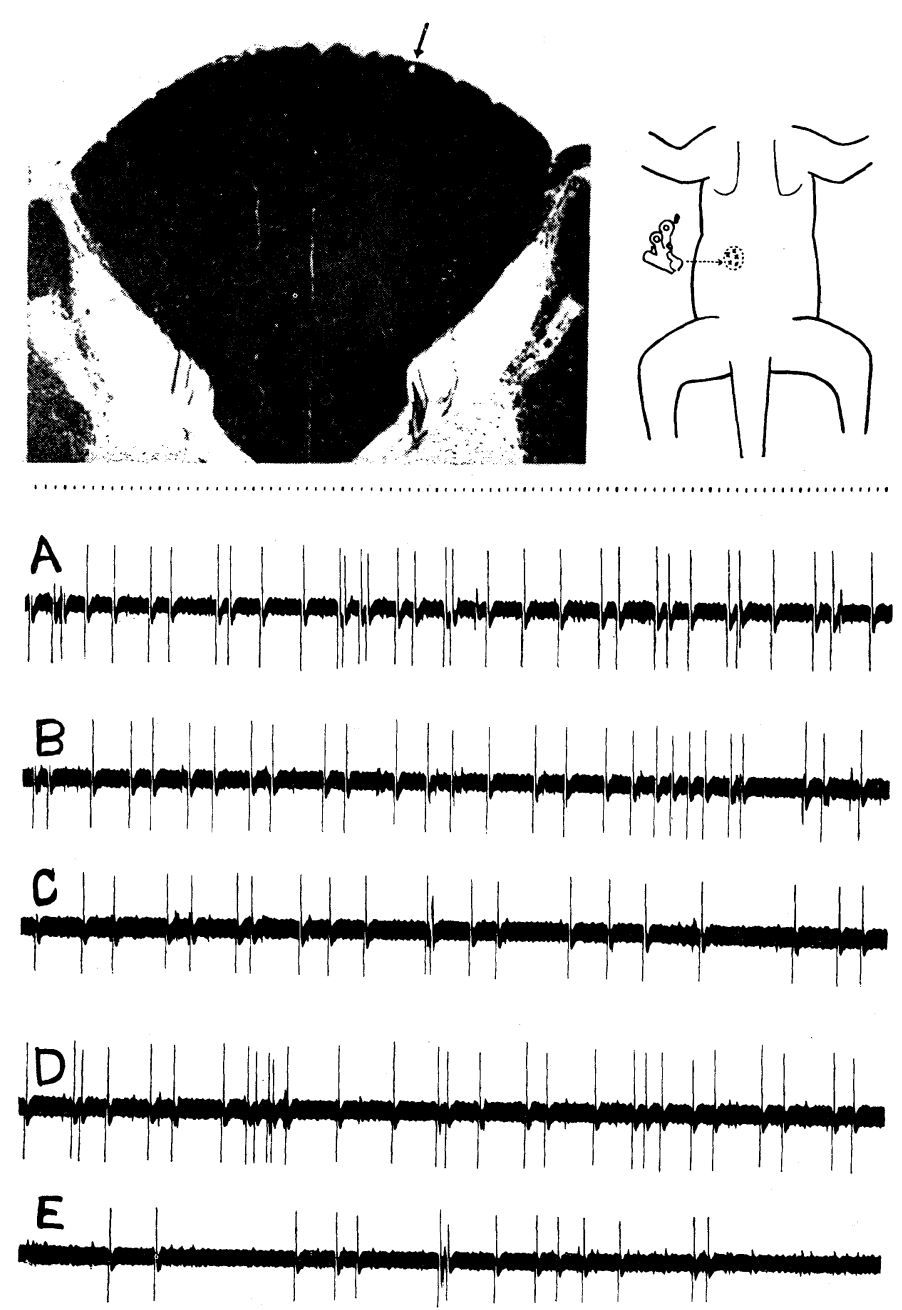

FIG. 3. Slowly adapting impulse discharges evoked by pinching the skin with a spring-hinged paper clip. Receptive field is indicated by a circle on the left loin in the sketch. Time in $1 / 120 \mathrm{sec}$.

$A$ : Record immediately after the application of clip which was left nipping on the receptive area.

$B-E$ : Records taken every 10 minutes until the shift of electrode interrupted further recording. 
usually be eliminated by stripping off the skin of the receptive area. They might possibly comprise those originating in the skin as well as in the subcutaneous tissue. In regard to the construction of impulses or adaptation, we could hardly distinguish these slowly adapting afferents of the skin from other proprioceptive afferents related to a muscle or a joint.

3) Responses to stimulation of muscle, tendon or articular capsule

By moving joints, or applying pressure upon articular capsules, tendons or muscles, slowly adapting impulse discharges were obtained (fig. 4). In some cases tests were done after stripping off the skin of the receptive area. Although
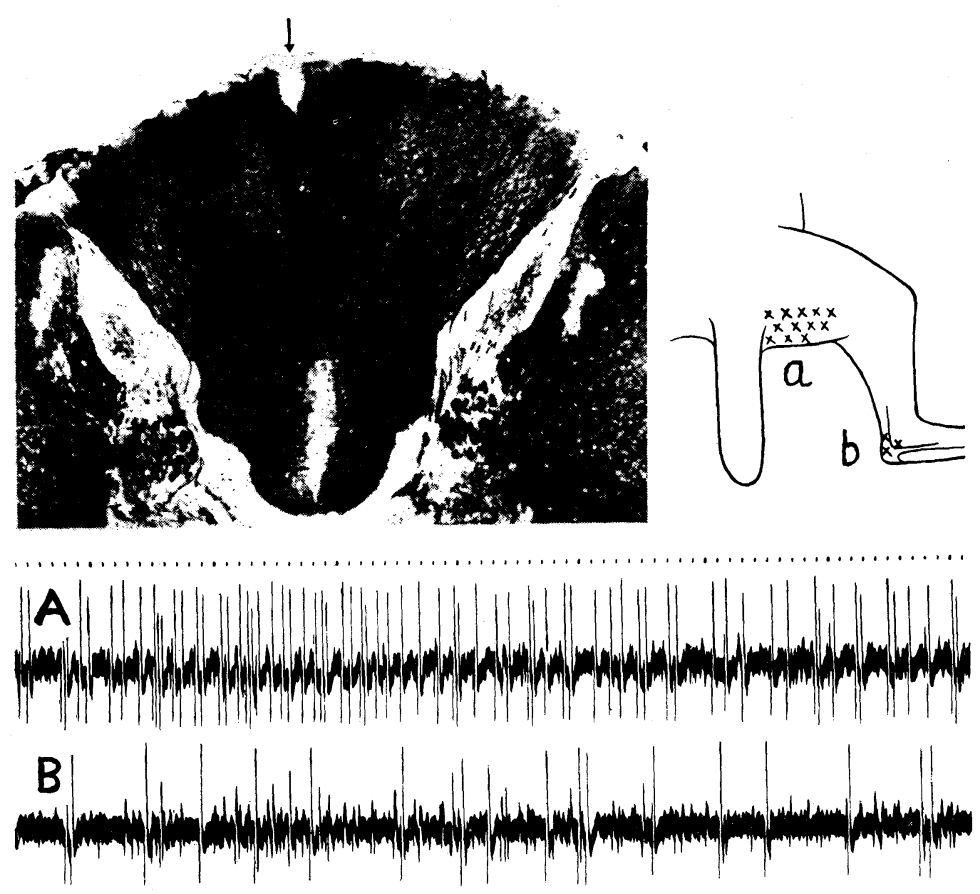

FIG. 4. Slowly adapting responses from proprioceptive afferents.

$A$ : Impulse discharges evoked by squeezing muscles of the dorsal part of the right thigh corresponding to " $a$ " in the sketch.

$B$ : Impulse discharges obtained by squeezing the right Achilles tendon corrsponding to " $b$ " in the sketch.

It was not fully clear whether responses $A$ and $B$ were evoked by different sources or by a single one. There was, however, no receptive field between both these areas. Time in $1 / 120 \mathrm{sec}$.

recordings from muscles were far less frequently obtained than those from joints or tendons, in certain animals we could determine the receptive field in the muscle itself by successive excisions. We were surprised by the fact that most of the responses obtained from the inner zone of Burdach's funiculus which were related to thoracic level, were proprioceptive in nature, because such slowly adapting impulse discharges which are elicitable by pressure on the thoracic 
wall, were spontaneously observed appearing synchronous with the respiratory movements.

\section{4) Responses to distension of the urinary bladder}

Slowly adapting impulse discharges responding to the filling of the urinary bladder were obtained from an extremely restricted area in Goll's funiculus lying superficially adjacent to septum medianum (fig. 5). The manipulation needed to insert the electrode in such a localized portion encountered far more difficulties than we had expected. As will be more extensively described later, the afferents from anus, perineum and tail converge closely to one another in the

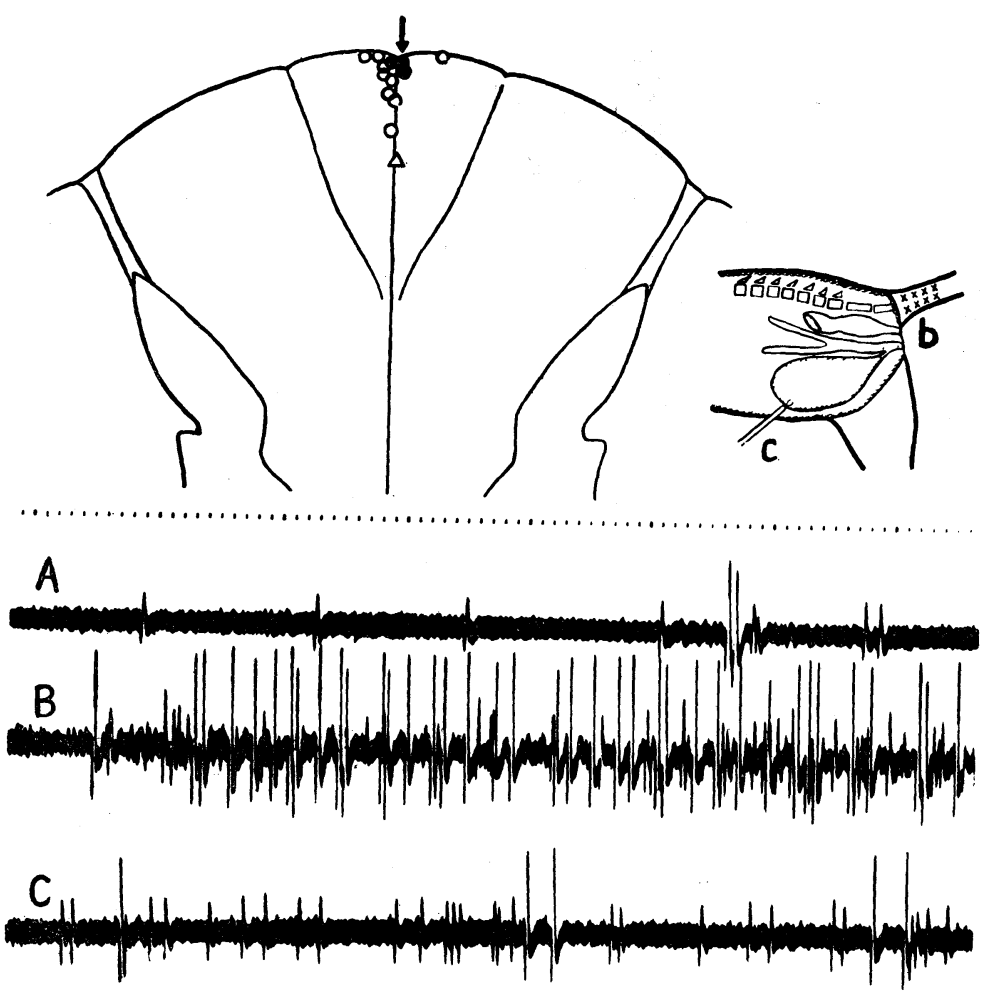

FIG. 5. Diagram illustrating the distribution of points responding to filling the urinary bladder (upper left) and an example of recording from the point indicated by the arrow (lower). Black circle, impulse discharges with relatively large spikes. White circle, impulse discharges with such small spikes that the distinction from noise level of the amplifier was made possible only by use of the loud speaker. At the point indicated by a triangle, spontaneous impulse discharges faded away in the course of filling the urinary bladder. Time in $1 / 120 \mathrm{sec}$.

$A$ : Spontaneous impulse discharges.

$B$ : Impulse discharges elicited by strokes over the left half of the base of the tail corresponding to " $b$ " in the sketch.

$C$ : Impulse discharges recorded from the same point subsequent to filling the urinary bladder. 
superficial layer of the medial part of Goll's funiculus. Therefore, most of the responses elicited by filling the urinary bladder were accompanied by responses to one of these portions. These circumstances could be utilized for judging whether the electrode was really located in the aimed portion or not. Namely, when the impulse volleys were induced by touching the tail, anus or perinuem, the location of the electrode was thought to be best for obtaining bladder response. Successful recordings were made 12 times with 10 animals. In one case the spontaneous impulse discharges observed in the part indicated with triangle in fig. 5 faded away, on the contrary, as we filled the bladder. The amplitude of spikes induced by vesical filling was usually far smaller than those of tactile or other afferents, the maximal value being $90 \mu \mathrm{V}$. Responses with large amplitude of impulses recorded in three animals were exclusively obtained in the most superficial part of Goll's funiculus closely adjacent to the septum medianum. In other cases responses were so faint that we could distinguish them from the noise level of the amplifler only by use of the loud speaker.

\section{TOPOGRAPHICAL AND FUNCTIONAL REPRESENTATION IN THE POSTERIOR FUNICULUS}

Responses were obtained ipsilaterally. On the tail, however, overlapping of the receptive areas on both sides was not infrequently observed, although confusion seemed to have been inevitable in such a restricted portion. Surveying the distribution of the points responded to stimulation of various parts of the body, we can recognize a tendency towards lamination corresponding to the source of stimuli.

\section{A. Topographical arrangement of sensory afferents in the second cervical cord corresponding to various body segments}

In the posterior funiculus, the medio-lateral arrangement of areas related to various parts of body is as follows:

1) Responses to filling the urinary bladder were obtained, as mentioned above, in the paramedian superficial portion of Goll's funiculus. Examples with spikes of relatively large amplitude were obtained in the most superficial layer close to the septum medianum (fig. 5).

2) Responses to stimuli to tail, perineum or external genitals were obtained in a triangular area connecting the middle of the dorsal surface of Goll's funiculus with the dorsal three-fourths of the septum medianum (fig. $6 \mathrm{~A}$ ). Responses of the tail could be much more frequently observed than those to perineum or external genitals. It is worth noting that the distribution of proprioceptive responses in the above-mentioned areas fairly coincides with the distribution of responses evoked by filling the urinary bladder.

3) Responses to stimuli to hind toes were obtained in an area occupying the posterior two-thirds of Goll's funiculus (fig. $6 \mathrm{~B}$ ). They were more easily elicitable from the hairy area than from the pads, and the regions surrounding nails seemed to be most sensitive. Responses to lateral toes were more frequently 
obtained than those to medial ones, but, in regard to the response from separate toes, no particular distribution could be deduced in this area.

4) Responses to stimuli to hind paws (except toes) were obtained scatteringly all over Goll's funiculus (fig. $6 C$ ). Responses to the plantar surface were more frequently obtained than those to the dorsal. It might be related to the fact that the very sensitive hairy area neighbouring the plantar cushion is included in the former.

5) Responses to stimuli to crura were most frequently obtained in the interior of Goll's funiculus (fig. $6 \mathrm{D}$ ).
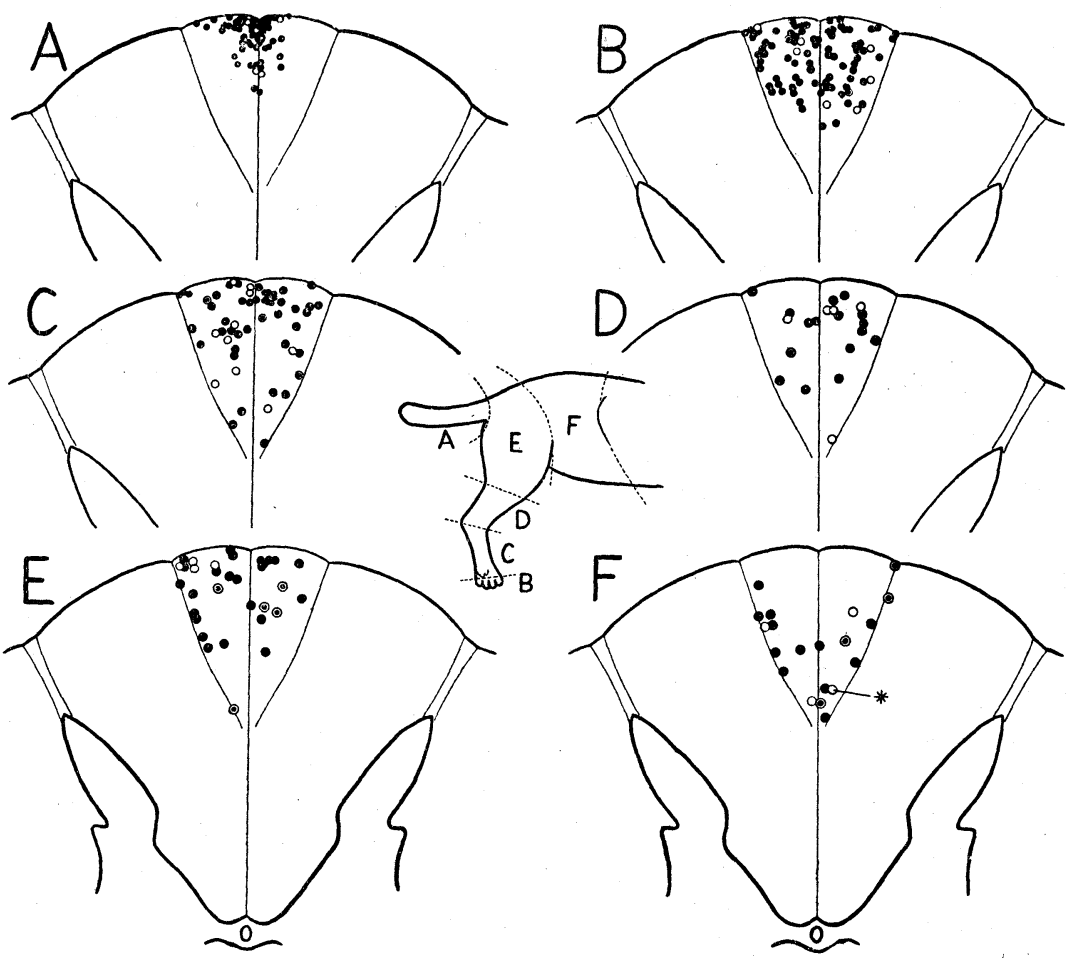

FIG. 6. Diagrams illustrating the distribution of points responding to stimulation of the part of body caudad to the 13th rib. Black circle, responses from tactile afferents. Dot in white circle, responses from pressure afferents. White circle, responses from proprioceptive afferents.

$A$ : Responses in tail, perineum or external genitals.

$B$ : Responses in hind toes.

$C$ : Responses in hind paws except toes.

$D$ : Responses in crura.

$E$ : Responses in thighs.

$F$ : Responses in loins or abdomen. From the point indicated with an asterisk, slowly adapting impulse discharges were obtained subsequent to strong pressure on the abdominal wall covering the stomach. Spontaneous impulse volleys synchronous with the arterial pulsations were also recorded here. 
6) Responses to stimuli to thighs were obtained in an area occupying the dorsal two-thirds of Goll's funiculus (fig. $6 E$ ).

7) Responses to stimuli to loins and abdomen were obtained in the ventral one-third of Goll's funiculus with a dorsal protrusion at its lateral border (fig. $6 \mathrm{~F})$. They approximately fill up the vacant space of Goll's funiculus in fig. $6 \mathrm{~B}$. Spontaneous discharges of impulse volleys synchronous with arterial pulsation were recorded from a point in this area (marked with asterisk in fig. $6 F$ ). From the same point slowly adapting responses were induced by pressure upon the abdominal wall covering the stomach. They might be related to muscle afferents of the abdominal wall.

8) Responses to stimuli to thoracic level were generally obtained in the medial border of Burdach's funiculus as well as in the ventral corner of Goll's funiculus (fig. $7 \mathrm{~A}$ ), and several responses obtained in relatively lateral area of the former were elicited by stimulation of pectoral muscles or muscles surrounding the axillar cavity. It is worth noting that the majority of responses were related to respiratory movements, and were proprioceptive in nature. Most responses concerned with touch on the skin were observed in the ventral corner of Goll's funiculus.

9) Responses to stimuli to fore toes were found in the medial part of Burdach's funiculus slightly apart from its medial border (fig. $7 B$ ). Contrary to the case of hind limbs, the medial toes seemed to be more sensitive than the lateral toes.

10) Responses io stimuli to forearms and fore paws except toes were obtained in the medial two-thirds of Burdach's funiculus (fig. $7 C, D$ ). Similar to the case of hind limbs, responses to the palmar side were predominant. Responses concerning proprioceptive afferents were more frequently obtained in the dorsal half of Burdach's funiculus, while those related to tactile afferents were concentrated in the ventral half (fig. $7 C$ ).

11) Responses to stimuli to upper arms, similar to those of pectoral muscles, were obtained dispersedly in the middle part of Burdach's funiculus (fig. $7 E$ ). It is worth noting that all of them were proprioceptive in nature. Most of them were obtained from the biceps side.

B. Spontaneous impulse discharges obscure in their receptive field (fig. $7 F$ ).

Spontaneous impulse discharges were frequently observed in the afferents of slow adaptation. But there were many cases in which spontaneous impulse discharges were observed, their receptive fields or origins remaining obscure in spite of scrupulous search. Among them those which were checked due to the large amplitude of pikes were frequently recorded in the lateral half of Burdach's funiculus or at its medial border. From points marked with " $P$ " in fig. $7 F$, impulse volleys discharged synchronously with arterial pulsation were obtained. 


\section{Distribution of responses in the posterior funiculus of first cervical cord} (fig. 8).

In the cat, at the first cervical level, Goll's funiculus undergoes a remarkable ventral translocation. Taking a fusiform shape, it is completely enveloped by Burdach's funiculus as noted by Kodama (17). Consequently, bilateral fibres
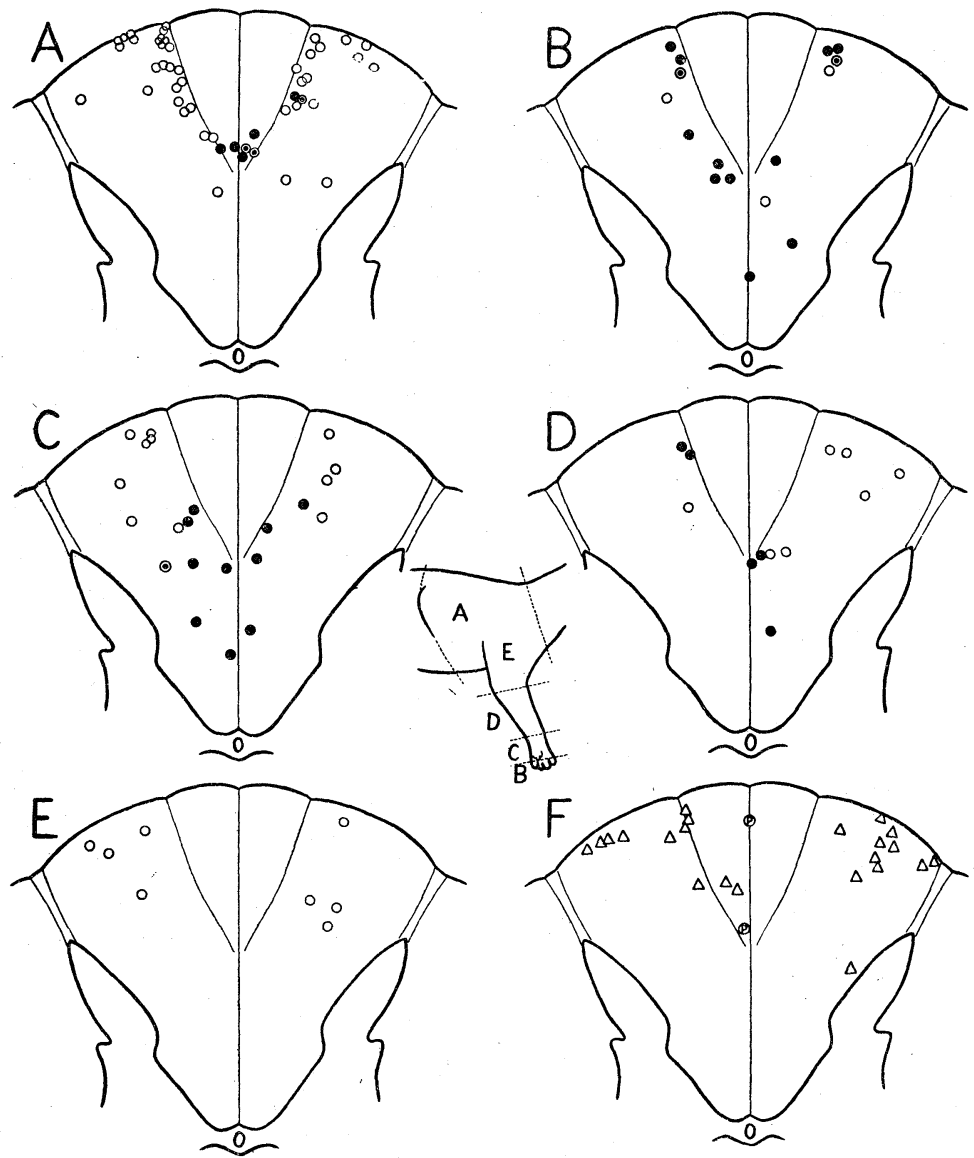

FIG. 7. Diagrams $A-E$ illustrate the distribution of points responding to stimulation of the part of body cephalad to the 13 th rib. Diagram $F$ indicates the site of points (indicated by triangle and $P$ ) where spontaneous impulse discharges obscure in their origin were recorded. At the point indicated by $P$, impulse volleys discharged synchronously with arterial pulsations were observed. As to other marks consult the legend of fig. 6 .

$A$ : Responses in chest or respiratory movements.

$B$ : Responses in fore toes.

$C$ : Responses in fore paws except toes.

$D$ : Responses in forearms.

$E$ : Responses in upper arms.

$F$ : Spontaneous impulse discharges obscure in their origin. 


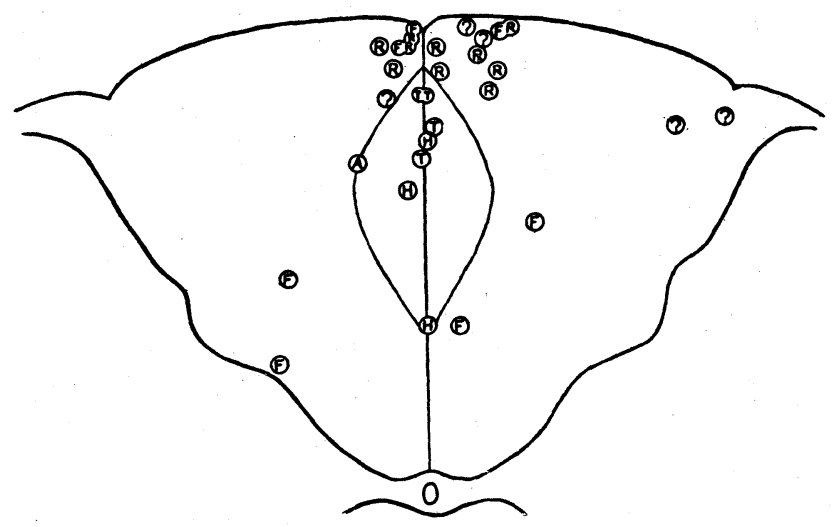

FIG. 8. Diagram illustrating distribution of responses obtained at the first cervical level. $A$, responses to loins or abdomen. $F$, to fore limb. $R$, to chest or discharges synchronous with respiration. $T$, to tail or perineum. ?, spontaneous impuls discharges obscure in their origin.

originating in the upper half of the body neighbour each other upon the dorsal surface of the posterior funiculus. Corresponding to this morphological fact, most of the responses obtained from the paramedian superficial layer of this level were related to the chest or fore limbs, and those related to the tail or perineum were found more ventrally than at the second cervical level.

\section{STATISTICAL REPRESENTATION OF RECORDINGS}

The site and nature of 509 responses obtained in 92 animals are shown in table 1. The predominance of number observed in Goll's funiculus is simply

TABLE 1

\begin{tabular}{|c|c|c|c|c|c|c|c|c|c|c|}
\hline & & \multicolumn{5}{|c|}{ Goll's funiculus } & \multicolumn{4}{|c|}{ Burdach's funiculus } \\
\hline & & \multicolumn{3}{|c|}{ Hind $\operatorname{limb}$} & \multirow{2}{*}{$\begin{array}{c}\text { Tail } \\
\text { perineum }\end{array}$} & \multirow{2}{*}{$\begin{array}{l}\text { Abdomen } \\
\text { loins }\end{array}$} & \multirow{2}{*}{ Chest } & \multicolumn{3}{|c|}{ Fore limb } \\
\hline & & Toe & Paw & Others & & & & Toe & Paw & Others \\
\hline \multicolumn{2}{|c|}{$\begin{array}{l}\text { Proprioceptive } \\
\text { afferents }\end{array}$} & $(2.1 \%)$ & $\begin{array}{c}11 \\
(3.3 \%)\end{array}$ & $\begin{array}{c}9 \\
(2.7 \%)\end{array}$ & $\stackrel{5}{(1.5 \%)}$ & $(0.9 \%$ & $\begin{array}{c}55 \\
(32.0 \%)\end{array}$ & $\left(\begin{array}{c}6 \\
(3.5 \%)\end{array}\right.$ & $(9.3 \%)$ & $\begin{array}{c}17 \\
(9.9 \%)\end{array}$ \\
\hline \multicolumn{2}{|c|}{$\begin{array}{c}\text { Pressure } \\
\text { afferents of skin }\end{array}$} & $(0.9 \%)$ & $\begin{array}{c}6 \\
(1.8 \%)\end{array}$ & $\begin{array}{c}11 \\
(3.3 \%)\end{array}$ & $(2.1 \%)$ & $\begin{array}{l}5 \\
(1.5 \%)\end{array}$ & $\begin{array}{c}6 \\
(3.5 \%)\end{array}$ & $(0.6 \%)$ & $\left(\begin{array}{l}3 \\
(1.7 \%\end{array}\right.$ & $\begin{array}{c}0 \\
(0 \%)\end{array}$ \\
\hline \multirow{2}{*}{$\begin{array}{c}\text { Tactile } \\
\text { afferents }\end{array}$} & $\left|\begin{array}{c}\text { Hairy } \\
\text { area }\end{array}\right|$ & $\begin{array}{c}81 \\
(24.0 \%)\end{array}$ & $\begin{array}{c}36 \\
(11.7 \%)\end{array}$ & $\begin{array}{c}49 \\
(14.0 \%)\end{array}$ & $\begin{array}{c}56 \\
(16.0 \%)\end{array}$ & $\begin{array}{c}15 \\
(4.5 \%)\end{array}$ & $\begin{array}{c}8 \\
(4.7 \%)\end{array}$ & $\begin{array}{c}13 \\
(7.5 \%)\end{array}$ & $\left(\begin{array}{c}10 \\
(5.8 \%)\end{array}\right.$ & $\begin{array}{c}8 \\
(4.7 \%)\end{array}$ \\
\hline & Pad & $\begin{array}{r}1 \\
(3.8\end{array}$ & $\begin{array}{l}3 \\
8 \%)\end{array}$ & & . & & & & $\begin{array}{l}6 \\
5 \%)\end{array}$ & \\
\hline \multicolumn{2}{|c|}{$\begin{array}{l}\text { Bladder } \\
\text { afferents }\end{array}$} & \multicolumn{5}{|c|}{$\begin{array}{c}13 \\
(3.8 \%)\end{array}$} & & & & \\
\hline \multicolumn{2}{|c|}{$\begin{array}{l}\text { Spontaneous } \\
\text { discharges }\end{array}$} & \multicolumn{5}{|c|}{$\begin{array}{c}7 \\
(2.1 \%)\end{array}$} & \multicolumn{4}{|c|}{$\begin{array}{c}23 \\
(13.3 \%)\end{array}$} \\
\hline \multicolumn{2}{|c|}{ Total } & \multicolumn{5}{|c|}{$\begin{array}{c}337 \\
(100 \%)\end{array}$} & \multicolumn{4}{|c|}{$\begin{array}{c}172 \\
(100 \%)\end{array}$} \\
\hline
\end{tabular}


due to more frequent insertions of the electrode in the medial portion of the posterior funiculus relative to our special interest in pelvic visceral afferents. It should be noted that in regard to the proportion of tactile responses to proprioceptive ones, a great differecnce exists between Goll's and Burdach's funiculus. In Goll's funiculus the former preponderate, in Burdach's funiculus the latter.

\section{DISCUSSION}

The knowledge of sensory afferents in the central nervous system have been obtained mostly from clinical works, and discrepancies between human observations and animal experiments were frequently encountered. The posterior funiculus which represents the ganglio-bulbar connection is characterized by its laminated structure, hence discussion may be simplified.

The sensory function of the posterior funiculus was unequivocally elucidated in 1879 by Schiff (24). But the convincing and concrete steps were made by Fabritius (5), who proclaimed, through clinical observations, that the posterior funiculus mediates the proprioceptive as well as the tactile sensation. Fibres of the posterior funiculus have been generally thought to be concerned with the mediation of the tactile sensation of an epicritic nature. In our experiments, a subdivision of tactile afferents could be done, but the results would be quite similar to those obtained by Maruhashi et al. (21) in experiments of the peripheral nerve. Spikes of large amplitude, very quick adaptation, and smallness of receptive field (being particularly small on the ends of limbs) are features of tactile afferents in the posterior funiculus. The concept of tactile discrimination of the posterior funiculus fibres may be vigorously supported by these results.

According to Maruhashi et al. (21) peripheral nerve fibres mediating pressures can be classified into two types. One is thin $(3-5 \mu$ in diameter) and adapts slowly. The other, thick and myelinated, is found in subcutaneous tissue and, adapting quickly, responds to deep-reaching stimuli. In our experiments, impulse discharges which were evoked by pushing or pinching the skin adapted slowly. The amplitude of spikes was usually large, and the supposition is probable that the recordings were made on relatively thick fibres. Although some of these long lasting impulse discharges could be evoked by a slight pressure, it is likely that these responses were elicited by afferents in a relatively deep layer of the skin or in the subcutaneous tissue. If, as Twitchell (28) has pointed out, the cutaneous sensation is contributory for the performance of purposive movements, these deep-lying, slowly adapting pressure afferents may participate in the proprioception.

It is generally assumed that the posterior funiculus is also concerned with the mediation of proprioceptive impulses in the strict sense. As to joint afferents, Gardner and Noer (10) could confirm the participation of the posterior funiculus. In our experiments, too, following the artificial flexion or extension of joints, slowly adapting impulse disharges could be obtained from the posterior funiculus. They are supposed to have their origin mainly in the articular capsules or in the ligaments around them. Such responses were most frequently 
recorded at the thoracic level. This fact suggests to us that the posterior funiculus is also participating in the regulation of respiratory movements.

There have been discussions on muscle afferents in the posterior funiculus. According to Glees and Soler (12), fibres of Goll's funiculus attaining medulla in cat retain only 25 per cent of the total number of fibres which enter the spinal cord at the corresponding levels. Lloyd and McIntyre (20) have noted in experiments on cats that only the slowly conducting fibres from the hind limb muscles reach Goll's nucleus, while the fastest conducting fibres are synaptically connected with Clarke's column. Analysing the evoked potential in the cerebellum, Gardner and Noer (10) have assumed that few, if any, afferents from muscles ascend in the posterior funiculus to the medulla, and in regard to the muscle afferents the lateral fascicle may be of major importance. Morin and Haddad (23) and Morin and Gardner (22) noted that cerebellar evoked potential, subsequent to stimulation of nerves supplying muscles and joints, was not impaired by section of the posterior funiculus. Gardner and Morin (9) obtained similar results in the study of the cerebrum. Utilizing antidromic stimulation in decerebrate frogs, however, Holmgren (14) noted that a considerable number of cutaneous and muscle nerve fibres from the fore and hind limbs reach the medulla along the posterior funiculus. Brodal and Walberg (4), and Brodal and Kaada (3) have described ascending fibres in the pyramidal tract and assumed a proprioceptive function in it. Responses obtained in the posterior funiculus following stimulation of muscles were scanty in number in our experiments. In some cases, however, we could confirm the existence of the receptive field in the muscle itself by successive excisions after stripping off the skin. Unfortunately such a procedure could be successful only occasionally because of a shift of the electrode during the manipulation.

White (30) has initiated the opinion that some of the visceral sensations might take a course through the posterior funiculus, based upon the clinical experience that the sense of filling of the urinary bladder and rectum was spared even after the extensive bilateral section of the anterolateral fascicles. Amassian (2) has recorded in the posterior funiculus the potential of A beta type subsequent to electrical stimulation of the splanchnic nerve. The sites of recording in his experiments were indicated in the intermediate area between Goll's and Burdach's funiculus. Similar experiments were performed by Aider et al. (1), and analogous results were obtained. The responses to filling the urinary bladder in our experiments were obtained from the paramedian superficial layer of the posterior funiculus. Their spike heights were far smaller than those for tactile afferents. Although we were not able to confirm the relation between the magnitude of the spikes and the diameter of the fibre, because of the small amplitude of the spikes, the assumption is very likely that these afferents in the posterior funiculus may belong to the A beta group. Recently Harwood and Cress (13) have proposed the possibility of an uncrossed, nonsynaptic pathway between the posterior funiculus and the ipsilateral medial lemniscus, though their opinion is not necessarily convincing from the morphological point of view. Kuru (18) has demonstrated a special group of fibres in the posterior funiculus which, originating in the posterior root ganglia of the 
inferior cord, ascends in the paramedian portion of the posterior funiculus to terminate in grey matter closely lateral to the ala cinerea. The assumption may be justfied that the impulse discharges induced by filling the urinary bladder were yielded by this group of fibres, because the responses were obtained exclusively in the area corresponding to the site of these fibres.

It has been a well-known fact since Kahler (16) that, in the posterior funiculus, the longer the fibres are, the more medially they are arranged (Kodama (11), Therman (29)). In our experiments, however, in spite of a tendency of lamination, a relatively dispersed distribution of responses to any portion of the body was recognized. Such a result should be related to the dermatoma of the animal.

Spontaneous impulse discharges, obscure in the receptive field, were most frequently recorded at the border between Goll's and Burdach's funiculus and in the lateral half of the latter. These areas fairly coincide with those where responses to chest and arm were obtained. In our experience, slowly adapting afferents were frequently accompanied by remarkable spontaneous impulse discharges. Upon the chest wall and in fore limbs the predominance of proprioceptive afferents was noted. At the 2nd cervical level fibres corresponding to neck and fore limb are distributed in the lateral part of Burdach's funiculus. They are said to be connected with Monakow's nucleus which is proprioceptive in function (Ferraro and Barrera (6)). The above-mentioned distribution of points from which spontaneous discharges were obtained might be related to these circumstances.

The predominance in number of responses in Goll's funiculus as demonstrated in table 1, is simply conseqent upon our endeavour to aim at the midmost portion of the posterior funiculus concerning responses to filling the urinary bladder. But it is worth noting that the proportion of tactile responses to proprioceptive responses differs markedly between Goll's and Burdach's funiculus. While the response to tactile stimuli preponderates in the former, those from proprioceptive afferents are predominant in the latter. Recent experiments carried out in our laboratory demonstrated that the circumstances are quite the reverse in the dorsal superficial layer of the lateral fascicle which corresponds to the spino-cerebellar tract. Namely, in this portion, in regard to the cranial half of the body, responses to tactile stimuli were more frequently obtained than those from proprioceptive afferents, and, in regard to the caudal half of the body, vice versa. The posterior funiculus and the spino-cerebellar tract seem, therefore, to compensate each other.

\section{SUMMARY}

Utilizing a silver microelectrode of $5-10 \mu$ in diameter insulated by a glass coating, impulse discharges subsequent to adequate stimuli on various parts of the body were recorded from the cervical posterior funiculus of cat and their arrangement was studied.

Conclusions are as follows:

1) Responses were obtained ipsilaterally and the forms of spikes could be classified into two types. One is thought to be related to nerve fibre and the 
other to nerve cell.

2) Responses to touch on the skin or hairs were most frequently obtained. In them, the amplitude of spikes was generally large and adaptation was very quick. Receptive areas for them were fairly localized, particularly restricted on the distal ends of limbs.

3) Impulse discharges responding to push or pull of the skin were tonic, adapting slowly. The physiological function of these afferents may be partly proprioceptive.

4) Among proprioceptive afferents, which generally adapted slowly, those for muscles were far less frequently encountered than those for articular capsules or tendons.

5) In Goll's funiculus, responses from tactile afferents were far more frequently obtained than those from proprioceptive afferents. The circumstances were quite opposite in regard to Burdach's funiculus. The majority of responses from the thoracic level seems to be concerned with respiratory movements of the chest.

6) From a localized superficial portion of Goll's funiculus closely adjacent to the septum medianum, slowly adapting impulse discharges were obtained subsequent to filling the urinary bladder. Their spike apperances were far smaller than those for tactile afferents.

7) The medio-lateral arrangement, upon the transverse section of the second cervical cord, of those parts of the body from which the responses were obtained was as follows: (a) urinary bladder, (b) tail or perineum, (c) toes of hind limbs, (d) distal half of hind limbs except toes, (e) proximal half of hind limbs, (f) loins or abdomen, $(\mathrm{g})$ chest, $(\mathrm{h})$ toes of fore limbs, (i) distal half of fore limbs except toes, (j) proximal half of fore limbs.

8) Spontaneous impulse discharges, which were obscure in their receptive fields, were frequently recorded in the lateral half of Burdach's funiculus and in an area between Goll's and Burdach's funiculus. They are assumed to be related to slowly adapting afferents and to be proprioceptive in nature.

The expenses for this work were defrayed by a grant for scientific research from the Ministry of Education.

\section{REFERENCES}

1. Aidar, O., Geohegan, W. A. AND UngewitTer, L. H. Splanchnic afferent pathways in the central nervous system. J. Neurophysiol. 15: 131-138, 1952.

2. AMASSIAN, V. E. Fiber groups and spinal pathways of cortically represented visceral afferents. J. Neurophysiol. 14: 445-460, 1951.

3. BRODAL, A. AND KAADA, B. R. Exteroceptive and proprioceptive ascending impulses in pyramidal tract of cat. J. Neurophysiol. 16: 567-586, 1953.

4. Brodal, A. AND Walberg, F. Ascending fibers in pyramidal tract of cat. Arch. Neurol. Psychiat., Chicago 68: 755-775, 1952.

5. FABRitius, H. Zur Frage nach der sensiblen Leitung im menschlichen Rückenmark. Mschr. Psychiatr. 31 : 103-134, 279-304, 376-394, 463-487, 546-597, 1912.

6. FERraro, A. AND BARRERA, S. E. Posterior column fibers and their termination in Macacus rhesus. J. comp. Neurol. 62: 507-530, 1935. 
7. FoeRSTER, O. Symtomatologie der Erkrankungen des Rückenmarks und seiner Wurzeln. Bumke-Foerster's Handbuch der Neurologie. Bd. 5. Berlin, 366-367, 1936.

8. GARDNER, E. AND HADDAD, B. Pathways to the cerebral cortex for afferent fibers from the hindleg of the cat. Am. J. Physiol. 172: 475-482, 1953.

9. GARDNER, E. D. AND MORIN, F. Spinal pathways for projection of cutaneous and muscular afferents to the sensory and motor cortex of the monkey (Macaca Mulatta). Am. J. Physiol. 174 : 149-154, 1953.

10. Gardner, E. AND Noer, R. Projection of afferent fibers from muscles and joint to the cerebral cortex of the cat. Am. J. Physiol. 168: 437-441, 1952.

11. Gasser, H. S. AND GRAham, H. T. Potentials produced in the spinal cord by stimulation of dorsal roots. Am. J. Physiol. 103 : 303-319, 1933.

12. GLEES, P. AND SOLER, J. Fibre content of the posterior column and synaptic connection of nucleus gracilis. Z. Zellforsch. 36: 381-400, 1951.

13. HARWOOD, T. H. AND CRESS, R. H. Activity in medulla elicited by electrical stimulation of posterior funiculus of spinal cord in cat. J. Neurophysiol. 17: 157-166, 1954.

14. Holmgren, B. Conduction along the dorsal tracts of the spinal cord. J. Physiol. 123 : 324-337, 1954.

15. HURSH, J. B. Relayed impulses in ascending branches of dorsal root fibers. J. Neurophysiol. 3 : 166-174, 1940.

16. KAHLER, O. Über die Veränderungen, welche sich im Rückenmarke in Folge einer geringsgradigen Compression entwickeln. Nebst einem die secundäre Degeneration im Rückenmarke des Hundes betreffenden Anhang. Z. Heilk. 3: 187-232, 1882.

17. KoDAMA, Y. Über das zentrale Verhalten der Hinterwurzelfasern bei der Katze. Fol. Anat. Jap. 21 : 291-334, 1942.

18. KURU, M. On the pelvic equivalent of the sensory vagus. Further contributions to the study of the sacro-bulbar connections and their relation to the bulbar vasomotor centers. Jap. J. Physiol. 1 : 240-253, 1951.

19. KURU, M., Yamamoto, S. AND Sugihara, S. On participation of the fibres of posterior funiculus in the mediation of the visceral sensations from organs in the pelvic cavity. A study on function of the "Pelvic vagus." (preliminary report). Proc. Jap. Acad. 29 : 230-233, 1953.

20. Lloyd, D. P. C. AND MCINTyRe, A. K. Dorsal column conduction of group I muscle afferent impulses and their relay through Clarke's column. J. Neurophysiol. 13: 39-54, 1950.

21. Maruhashi, J., Mizuguchi, K. AND TASAKI, I. Action current in single afferent nerve fibres elicited by stimulation of the skin of the toad and the cat. J. Physiol. 117: 129-151, 1952.

22. MoRin, F. AND GARDNER, E. D. Spinal pathways for cerebellar projections in the monkey (Macaca Mulatta). Am. J. Physiol. 174: 155-161, 1953.

23. MORIN, F. AND HADDAD, B. Afferent projections to the cerebellum and the spinal pathways involved. Am. J. Physiol. 172: 497-510, 1953.

24. Schiff. Über die Leitung der Gefühlseindrücke im Rückenmark. Zbl. Nervenhk. usw. 2: 509-513, 1879.

25. SJÖQvist, O. AND WeInstein, E. A. The effect of section of the medial lemniscus on proprioceptive functions in chimpanzees and monkeys. J. Neurophysiol. 5:67-74, 1942.

26. TASAKI, I. Properties of myelinated fibers in frog sciatic nerve and in spinal cord as examined with microelectrodes. Jap. J. Physiol. 3 : 73-94, 1952.

27. Theman, P. O. Transmission of impulses through the Burdach nucleus. J. Neurophysiol. 4 : 153-166, 1941.

28. Twitchell, T. E. Sensory factors in purposive movement. J. Neurophysiol. 17: 239- 
252, 1954.

29. WALkeR, A. E. AND WEAvER, T. A. The topical organization and termination of the fibers of the posterior columns in macaca mulatta. J. comp. Neurol. $76: 145-158,1942$.

30. White, J. C. Sensory innervation of the viscera. Studies on visceral afferent neurones in man based on neurosurgical procedures for the relief of intractable pain. Res. Publ. Ass. Nerv. Ment. Dis. 23: 373-390, 1943.

31. Woodbury, J. W. Direct membrane resting and action potentials from single myelinated fibers. J. cell. a. comp. Physiol. 39 : 323-339, 1952. 